\title{
Higher Mode Vertical Vibration of Giant Tanker
}

(2 nd Report)

\author{
Koji Kagawa*, Member Katsuo Ohtaka*, Member
}

\begin{abstract}
Summary
In the higher mode vibration of giant tankers the transverse section of the ship deforms elastically, and the side shell and the longitudinal bulkhead show the individual deflection, as explained in the first report ${ }^{3)}$. In this report, the hydrodynamic inertia has been investigated theoretically for such a case, and the results shows that the hydrodynamic inertia has three components, i.e., added mass of water for longitudinal bulkhead member, that for side shell member and the hydrodynamic coupling term. Theoretical estimation of these three components nearly coincides with the experiment.

The calculation of the natural frequency of the ship using the hydrodynamic inertia derived above agrees with the experiment in a full scale ship with $5 \%$ of errors.

The calculation of response to a sinusoidal force has been also carried out, the results of which show that, although the calculation agrees with experiment qualitatively, more study is necessary to acquire the precise result.
\end{abstract}

\section{Introduction}

The deformation of the transverse section of the ship should be considered in the study of the higher mode vertical vibration of the giant taker ${ }^{1) \sim 4}$. In this report, the followings are studied based upon the results of the 1st report ${ }^{3)}$.

(a) added weight of water for higher mode vibration

(b) natural frequency and response of higher mode vibration

The ship hull is simulated by the two parallel beams elastically connected, which is the same that in the 1 st report. Each beam represents the longitudinal bulkhead and the side plating respectively and the connecting spring the transverse members. The transfer matrix method developed in the 1 st report to calculate the frequency and the response of the ship is used for the numerical calculation in this report. Antisymmetric deformation of the transverse section of the ship is not taken into account.

\section{Added virtual weight of water}

The ship vibrates approximately as a beam in the lower mode where the transverse section of the ship oscillates vertically without elastic deformation as shown in Fig. 2.1 (a). In this case, an added virtual mass of water of unit length of the ship is represented by $J \cdot m_{w}$, where $J$ is a three-dimensional correction factor and $m_{w}$ is the two-dimensional added virtual mass per unit length and is shown as follows :

$$
m_{w}=\frac{1}{2} \rho \pi b^{2} C_{V 0}
$$

where

$\rho:$ density of water

* Nagasaki Technical Institute, Technical Headquarters, Mitsubishi Heavy Industries, Ltd. 


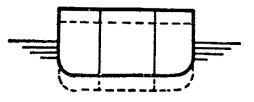

(a) beam theory

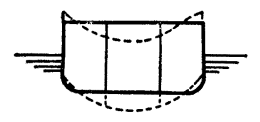

(b) higher mode vibration

Fig. 2.1 Vibration mode of cross section

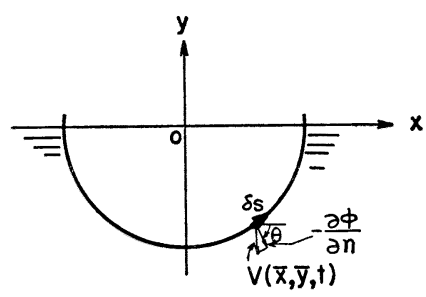

Fig. 2.2 Cross section of floating body $b$ : half breadth of section

$C_{V 0}$ : hydrodynamic coefficient

In the case of higher mode vibration, however, the transverse section deforms elastically as shown in Fig. 2.1 (b) and, as was pointed out by $\mathrm{Kumai}^{8)}$ and Matsuura ${ }^{10)}$, it is not correct to adopt the equation (2.1). In this report, the treatment of hydrodynamic inertia effect of surrounding water for this kind of vibration is presented, under the assumption that the flow is two-dimensional. A section of the two-dimensional floating body is shown in Fig. 2.2. The hydrodynamical boundary condition for the vertical vibration of the section with elastic deformation is drawn as follows.

$$
\begin{aligned}
-\frac{\partial \phi}{\partial n} & =-\frac{\partial \psi}{\partial s}=V_{(\bar{x}, \bar{y}, t)} \frac{\partial \bar{x}}{\partial s} \\
\therefore \quad \phi & =-\int_{0}^{\bar{x}} V_{(\bar{x}, \bar{y}, t)} d \bar{x}+\text { const }
\end{aligned}
$$

where

$$
\begin{aligned}
& \phi: \text { velocity potential } \\
& \psi \text { : stream function }
\end{aligned}
$$

$V_{(\bar{x}, \bar{y}, t)}$ : vertical velocity of elastic deflection of boundary shown in Fig. 2.2

$(\bar{x}, \bar{y})$ : coordinate of a point on the boundary

It is assumed that the transverse section of the ship in the $Z$-plane is the conformal transformation of unit circle in $\zeta$-plane through Lewis' formula (so-called the Lewis Forms) as follows.

where

$$
\begin{aligned}
& z=b_{0}\left(\zeta+\frac{a_{1}}{\zeta}+\frac{a_{3}}{\zeta^{3}}\right) \\
& z=x+i y, \quad \quad \zeta=r e^{i \theta} \\
& b_{0}=\frac{b}{4}\left\{3(1+\lambda)-\sqrt{(1+\lambda)^{2}+8 \lambda\left(1-\frac{4 \sigma}{\pi}\right)}\right\} \\
& a_{1}=\frac{1-\lambda}{2 b_{0}} b \\
& \lambda=\frac{d}{b} \quad \quad a_{3}=\frac{1+\lambda}{2 b_{0}} b-1 \\
& d: \text { draft } \\
& S: \text { area of section under water surface }
\end{aligned}
$$

Another assumption is that the vibration mode of ship section in $Z$-plane is expressed by the following quadratic equation as shown in Fig. 2.3.

$$
V(\bar{x}, \bar{y}, t)=\frac{V_{1}}{e}\left\{e+(1-\alpha)\left(x_{1}^{2}-\bar{x}^{2}\right)\right\}
$$

where

$$
e=b^{2}-x_{1}{ }^{2}, \quad \alpha=\frac{V_{2}}{V_{1}}
$$

$x_{1}$ : position of the longitudinal bulkhead

$V_{1}$ : vertical velocity of the longitudinal bulkhead

$V_{2}$ : vertical velocity of the side plating

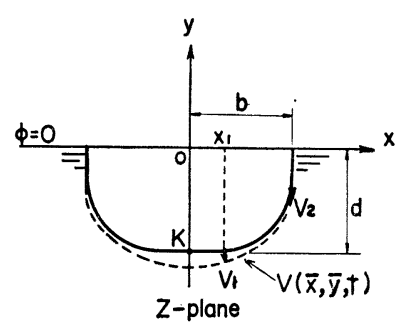

Fig. 2.3 Elastic deformation of Lewis form

Substituting the equation (2.5) into the equation (2.3), the boundary condition for Lewis form section is given as follows : 


$$
\psi=-\frac{V_{1}}{\epsilon}\left[\left\{e+(1-\alpha) x_{1}^{2}\right\} \bar{x}-\frac{(1-\alpha)}{3} \bar{x}^{3}\right]+\text { const. }
$$

where $\quad \bar{x}=b_{0}\left\{\left(1+a_{1}\right) \cos \theta+a_{3} \cos 3 \theta\right\}$

Using the above-metioned boundary condition, the volocity potential and the stream function of the half-immersed Lewis form section are derived as follows :

$$
\begin{aligned}
& \phi=\sum_{m} \frac{1}{r^{m}} S_{m} \sin m \theta, \quad m=1,3,5,7,9 \\
& \psi=\sum_{m} \frac{1}{r^{m}} S_{m} \cos m \theta, \quad m=1,3,5,7,9
\end{aligned}
$$

where $\quad S_{m}=f_{m} V_{1}+h_{m} V_{2}$

$$
\begin{aligned}
& f_{1}=-\frac{1}{e}\left[\left\{e+x_{1}^{2}\right\} b_{0}\left(1+a_{1}\right)-\frac{1}{3} b_{0}^{3}\left\{\frac{3}{4}\left(1+a_{1}\right)^{3}+\frac{3}{4}\left(1+a_{1}\right)^{2} a_{3}+\frac{3}{2}\left(1+a_{1}\right) a_{3}^{2}\right\}\right] \\
& h_{1}=-\frac{1}{e}\left[-x_{1}^{2} b_{0}\left(1+a_{1}\right)+\frac{1}{3} b_{0}^{3}\left\{\frac{3}{4}\left(1+a_{1}\right)^{3}+\frac{3}{4}\left(1+a_{1}\right)^{2} a_{3}+\frac{3}{2}\left(1+a_{1}\right) a_{3}^{2}\right\}\right] \\
& f_{3}=-\frac{1}{e}\left[\left\{e+x_{1}^{2}\right\} b_{0} a_{3}-\frac{1}{3} b_{0}^{3}\left\{\frac{1}{4}\left(1+a_{1}\right)^{3}+\frac{3}{2}\left(1+a_{1}\right)^{2} a_{3}+\frac{3}{4} a_{3}^{3}\right\}\right] \\
& h_{3}=-\frac{1}{e}\left[\left\{-x_{1}^{2} b_{0} a_{3}+\frac{1}{3} b_{0}^{3}\left\{\frac{1}{4}\left(1+a_{1}\right)^{3}+\frac{3}{2}\left(1+a_{1}\right)^{2} a_{3}+\frac{3}{4} a_{3}^{3}\right\}\right]\right. \\
& f_{5}=\frac{1}{3 e} b_{0}^{3}\left\{\frac{3}{4}\left(1+a_{1}\right)^{2} a_{3}+\frac{3}{4}\left(1+a_{1}\right) a_{3}^{2}\right\} \\
& h_{5}=-f_{5} \\
& f_{7}=\frac{1}{4 e} b_{0}^{3} \cdot a_{3}^{2}\left(1+a_{1}\right) \\
& h_{7}=-f_{7} \\
& f_{9}=\frac{1}{12 e} b_{0}{ }^{3} \cdot a_{3}{ }^{3} \\
& h_{9}=-f_{9}
\end{aligned}
$$

The kinetic energy of the fluid is experessed as follows :

where

$$
T=\frac{1}{2}\left(m_{W 1} V_{1}^{2}+m_{W 2} V_{2}^{2}+2 m_{W 3} V_{1} V_{2}\right)
$$

$$
\begin{aligned}
& m_{W 1}=\frac{\rho \pi}{2} \sum m f_{m}^{2} \equiv \frac{\rho \pi}{2} b^{2} C_{V 1}\left(\lambda, \sigma, \frac{x_{1}}{b}\right) \\
& m_{W 2}=\frac{\rho \pi}{2} \sum m h_{m}^{2} \equiv \frac{\rho \pi}{2} b^{2} C_{V 2}\left(\lambda, \sigma, \frac{x_{1}}{b}\right) \\
& m_{W 3}=\frac{\rho \pi}{2} \sum m f_{m} h_{m} \equiv \frac{\rho \pi}{2} b^{2} C_{V 3}\left(\lambda, \sigma, \frac{x_{1}}{b}\right)
\end{aligned}
$$

Thus, hydrodynamic effect of water for the higher mode vibration of the ship may be expressed by the above-mentioned $m_{W 1}, m_{W 2}$ and $m_{W 3}$. Neglecting the three dimesional flow of water, the kinetic energy of the water surrounding the ship is expressed by the following equation.

$$
T_{W}=\frac{1}{2} \int_{l_{1}}^{l_{2}}\left\{m_{W 1}\left(\frac{\partial y_{1}}{\partial t}\right)^{2}+m_{W 2}\left(\frac{\partial y_{2}}{\partial t}\right)^{2}+2 m_{W 3}\left(\frac{\partial y_{1}}{\partial t}\right)\left(\frac{\partial y_{2}}{\partial t}\right)\right\} d x
$$

where $y_{1}$ : deflection of longitudinal bulkhead

$y_{2}$ : deflection of side plating

On the other hand, the kinetic energy and the strain energy of the ship are as follows :

$$
\begin{gathered}
T_{H}=\frac{1}{2} \int_{l_{1}}^{l_{2}}\left\{m_{1}\left(\frac{\partial y_{1}}{\partial t}\right)^{2}+m_{2}\left(\frac{\partial y_{2}}{\partial t}\right)^{2}+I_{m 1}\left(\frac{\partial \theta_{1}}{\partial t}\right)^{2}+I_{m 2}\left(\frac{\partial \theta_{2}}{\partial t}\right)^{2}\right\} d x \\
V=\frac{1}{2} \int_{l_{1}}^{l_{2}}\left\{E I_{1}\left(\frac{\partial \theta_{1}}{\partial x}\right)^{2}+E I_{2}\left(\frac{\partial \theta_{2}}{\partial x}\right)^{2}+k^{\prime} G A_{1}\left(\frac{\partial y_{1}}{\partial x}-\theta_{1}\right)^{2}\right. \\
\left.+k^{\prime} G A_{2}\left(\frac{\partial y_{2}}{\partial x}-\theta_{2}\right)^{2}+k\left(y_{2}-y_{1}\right)^{2}\right\} d x
\end{gathered}
$$


where $\quad m_{1}, m_{2}$ : mass per unit length of longitudinal bulkhead and side plating respectively

$I_{m_{1}}, I_{m_{2}}$ : mass moment of inertia per unit length of longitudinal bulkhead and side plating respectively

$E I_{1}, E I_{2}$ : bending rigidity of longitudinal bulkhead and side plating respectively

$k^{\prime} G A_{1}, k^{\prime} G A_{2}$ : shear rigidity of longitudinal bulkhead and side plating respectively

$\theta_{1}, \theta_{2}$ : bending slope of longitudinal bulkhead and side plating respectively

$k$ : connecting spring constant of transverse members per unit length of ship

The equation of motion is drawn by mean of the Hamilton's principle,

$$
\delta \int_{t_{1}}^{t_{2}}\left(T_{W}+T_{H}-V\right) d t=0
$$

Thus, the differential equation for the higher mode vibration is expressed as follows :

$$
\begin{gathered}
\boldsymbol{u}=\left\{y_{1}, y_{2}, \theta_{1}, \theta_{2}, V_{1}, V_{2}, M_{1}, M_{2}\right\} \\
\begin{array}{c}
d \boldsymbol{u} \\
d x
\end{array}=\boldsymbol{c u} \\
0
\end{gathered}
$$

where $\quad \boldsymbol{u}:$ column vector

$V_{1}, V_{2}$ : shearing force of longitudinal bulkhead and side plating respectively

$M_{1}, M_{2}$ : bending moment of longitudinal bulkhead and side plating respectively

$\omega$ : circular frequency

The equation (2.13) is the same as the equations (2.6), (2.7) and (2.8) in the 1 st report ${ }^{3)}$ except elements including $m_{W 1}, m_{W 2}$ and $m_{W 3}$ in the matrix $\boldsymbol{C}$. From the equation (2.13), the followings are concluded.

(a) $m_{W 1}$ and $m_{W 2}$ are the added mass of water to the longitudinal bulkhead and the side plating respectively.

(b) $m_{W 3}$ concerns to the hydrodynamic coupling.

The added mass of water for the higher mode vibration expressed by the above-mentioned $m_{W 1}, m_{W 2}$ and $m_{W 3}$ has the following relation with the added mass in the beam theory shown by the equation $(2.1)$.

$$
C_{V 0}=C_{V 1}+C_{V 2}+2 C_{V 3}
$$

The similar procedure can be applied to the rectangular section whose transforming formula is expressed as follows ${ }^{20)}$ :

$$
Z=M\left\{\boldsymbol{\zeta}+\sum_{m} \frac{1}{\zeta^{m}} A_{m}\right\}, \quad m=1,3,5,7,9,11
$$

where

$$
\begin{aligned}
M & =\frac{d}{\sin \varphi-\sum A_{m} \sin m \varphi} \\
\lambda & =\frac{\sin \varphi-\sum A_{m} \sin m \varphi}{\cos \varphi+\sum A_{m} \cos m \varphi} \\
A_{1} & =\cos 2 \varphi
\end{aligned}
$$


$A_{3}=-\frac{1}{6} \sin ^{2} 2 \varphi$

$A_{5}=-\frac{1}{10} \cos 2 \varphi \sin ^{2} 2 \varphi$

$A_{7}=-\frac{1}{56}\left(5 \cos ^{2} 2 \varphi-1\right) \sin ^{2} 2 \varphi$

$A_{9}=-\frac{1}{72}\left(7 \cos ^{2} 2 \varphi-3\right) \cos 2 \varphi \sin ^{2} 2 \varphi$

$A_{11}=-\frac{1}{176}\left(21 \cos ^{4} 2 \varphi-14 \cos ^{2} 2 \varphi+1\right) \sin ^{2} 2 \varphi$

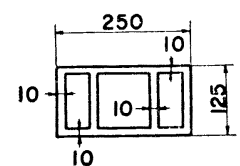

model A

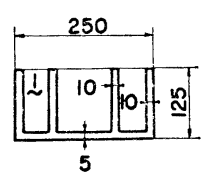

model B (a) transyerse section
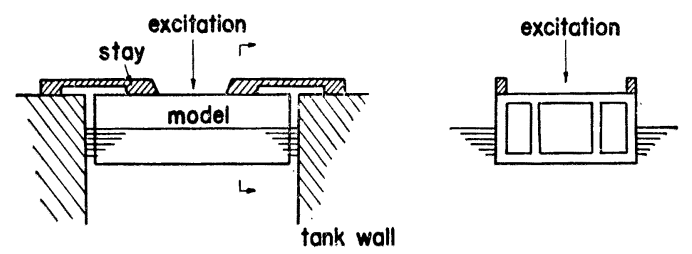

(b) suspension of model

Fig. 2.5 Acrylite models for added water experiment

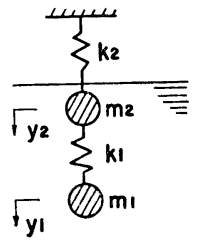

Fig. 2.6 Vibration in water of the mass-spring system

Numerical values of $C_{V 1}, C_{V 2}$ and $C_{V 3}$ are shown in Fig. 2.4. In order to check the above-mentioned results, the model experiment has been carried out. The models are made of acrylite and shown in Fig. 2.5. As the calculation is made for the two-dimersional flow, the model device is also arranged so as to keep the flow two-dimensional. The length of the
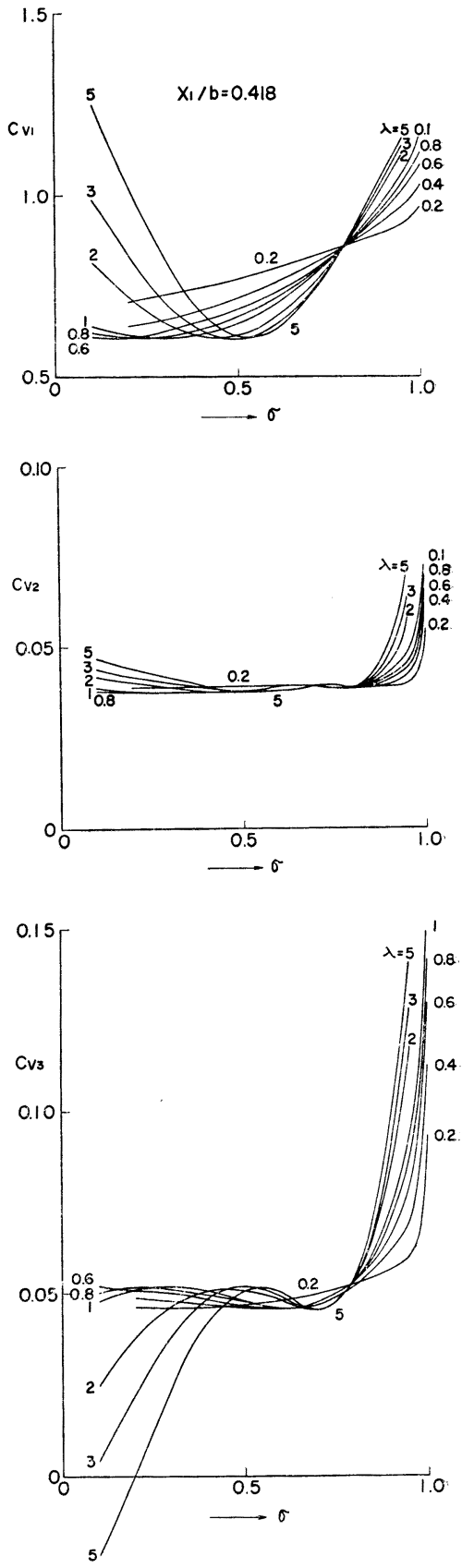

Fig. 2.4 Hydrodynamic coefficient for higher mode vibration model is so short compared with the breadth that every section of model undergoes the deformation like that shown in Fig. 2.1 (b). Thus, the model can be approximated for calculation by the massspring system of two degrees of freedom shown in Fig. 2.6, where $m_{1}$ and $m_{2}$ are the mass of the longitudinal bulkhead and the side plating respectively, $k_{1}$ is the connecting spring constant of transverse members and $k_{2}$ is the spring constant of the suspender. The equation of motion of the system is drawn as follows. 


$$
\left[\begin{array}{cc}
k_{1}-\omega^{2}\left(m_{1}+m_{W 1}\right), & -\left(k_{1}+\omega^{2} m_{W 3}\right) \\
-\left(k_{1}+\omega^{2} m_{W 3}\right), & \left(k_{1}+k_{2}\right)-\omega^{2}\left(m_{2}+m_{W 2}\right)
\end{array}\right]\left[\begin{array}{l}
y_{1} \\
y_{2}
\end{array}\right]=0
$$

Numerical values of models shown in Table 2.1. The mass of members located inside of the vertical planes through halfbreadth of wing tanks is assigned to the mass of the longititudinal bulkhead $\left(m_{1}\right)$ and the remainders to the mass of the side plating $\left(m_{2}\right)$. Values of added virtual mass of water $\left(m_{W 1}, m_{W 2}\right.$ and $\left.m_{W 3}\right)$ are estimated by the theoretical method mentioned above. Measured and calculated results are presented in Tables 2.2 and 2.3. The followings are seen in the tables.

(a) Calculated results agree with measured ones in qualitative tendency.

(b) The effect of the hydrodynamic inertia on the frequency is larger in the 1 st mode than in the 2 nd mode, as was pointed out by $\mathrm{Kumai}^{5}$.

(c) Discrepancy in 1 st mode presented in Table 2.3

Table 2.1 Numerical values of models

\begin{tabular}{|c|c|c|c|c|c|c|}
\hline & \multicolumn{3}{|c|}{ Model A } & \multicolumn{3}{|c|}{ Model B } \\
\hline$m_{1} g$ & \multicolumn{3}{|c|}{$3.18 \mathrm{~kg}$} & \multicolumn{3}{|c|}{$1.90 \mathrm{~kg}$} \\
\hline$m_{2} g$ & \multicolumn{3}{|c|}{$2.34 \mathrm{~kg}$} & \multicolumn{3}{|c|}{$1.65 \mathrm{~kg}$} \\
\hline$k_{1}^{*)}$ & \multicolumn{3}{|c|}{$12512 \mathrm{~kg} / \mathrm{cm}$} & \multicolumn{3}{|c|}{$1424 \mathrm{~kg} / \mathrm{cm}$} \\
\hline $\begin{array}{l}\text { Draft } \\
(\mathrm{cm})\end{array}$ & $\begin{array}{c}m_{w 1} g \\
(\mathrm{~kg})\end{array}$ & $\begin{array}{c}m_{w 2} g \\
(\mathrm{~kg})\end{array}$ & $\begin{array}{c}m_{w_{3}} g \\
(\mathrm{~kg})\end{array}$ & $\begin{array}{c}m_{w 1} g \\
(\mathrm{~kg})\end{array}$ & $\begin{array}{c}m_{w_{2}} g \\
(\mathrm{~kg})\end{array}$ & $\begin{array}{c}m_{w_{3}} g \\
(\mathrm{~kg})\end{array}$ \\
\hline 1.0 & 9.88 & 0.80 & 1.66 & & & \\
\hline 3.0 & & & & 10.53 & 0.92 & 1.96 \\
\hline 4.0 & & & & 10.80 & 0.98 & 2.05 \\
\hline 4.9 & 10.98 & 1.02 & 2.15 & & & \\
\hline 10.0 & 11.90 & 1.17 & 2.52 & & & \\
\hline
\end{tabular}

* $k_{1}$ is so determined that the calculated frequency coincides with the measured one in the case A-1 without suspender $\left(k_{2}=0\right)$. may be partly caused by the error in estimation of the spring constant of the suspender $\left(k_{2}\right)$, which has the predominant effect on the frequency of the 1 st mode and was estimated by the static deflection test, whereas the spring constant of the connecting spring $\left(k_{1}\right)$ has the predominant effect on the frequency of the 2 nd mode and was estimated by the vibration test.

Another cause may be in the inadequate rigidness of the model device.

(d) It can be accpetable for simplification to neglect $m_{W 3}$, though it slightly makes error larger.

In the actual ship the flow surrounding a ship is three dimensional and the correction factor should be considered. In the case of vibration based on the beam theory there is a vibration test on a

Table 2.2 Measured and calculated frequencies of models

\begin{tabular}{|c|c|c|c|c|c|c|c|c|c|c|c|c|c|}
\hline & & & & \multicolumn{4}{|c|}{ Model A } & \multicolumn{6}{|c|}{ Model B } \\
\hline & & & & \multicolumn{2}{|c|}{$\begin{array}{c}\text { Measured } \\
\text { freq. }\end{array}$} & \multicolumn{2}{|c|}{$\begin{array}{l}\text { Calculated } \\
\text { freq. }\end{array}$} & \multicolumn{2}{|c|}{$\begin{array}{c}\text { Measured } \\
\text { freq. }\end{array}$} & \multicolumn{2}{|c|}{$\begin{array}{l}\text { Calculated } \\
\text { freq. }\end{array}$} & \multicolumn{2}{|c|}{$\begin{array}{r}\text { Caclulated } \\
\text { freq. } * *\end{array}$} \\
\hline \multicolumn{2}{|c|}{ Case } & $\begin{array}{l}\text { Draft } \\
(\mathrm{cm})\end{array}$ & Suspension & $\begin{array}{l}1 \mathrm{st}^{*} \\
\text { mode } \\
(\mathrm{cps})\end{array}$ & $\begin{array}{l}2 \text { nd* }^{*} \\
\text { mode } \\
(\mathrm{cps})\end{array}$ & $\begin{array}{c}1 \mathrm{st} \\
\text { mode } \\
(\mathrm{cps})\end{array}$ & $\begin{array}{l}2 \text { nd } \\
\text { mode } \\
(\text { cps })\end{array}$ & $\begin{array}{c}1 \mathrm{st} \\
\text { mode } \\
(\mathrm{cps})\end{array}$ & $\begin{array}{c}2 \text { nd } \\
\text { mode } \\
(\mathrm{cps})\end{array}$ & $\begin{array}{c}1 \mathrm{st} \\
\text { mode } \\
(\mathrm{cps})\end{array}$ & $\begin{array}{c}2 \text { nd } \\
\text { mode } \\
(\mathrm{cps})\end{array}$ & $\begin{array}{r}1 \mathrm{st} \\
\text { mode }\end{array}$ & 2 nd \\
\hline 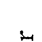 & A-1 & & Sponge mat & & 480 & & 480 & & 200 & & 200 & \multirow{3}{*}{\multicolumn{2}{|c|}{ do. }} \\
\hline สี & A-2 & & Steel*** & 75 & 455 & 90.1 & 492.4 & 75 & 192 & 94.4 & 244.2 & & \\
\hline$\Xi$ & $A-3$ & & Acrylite*** & 23 & 472 & 19.3 & 480.5 & 23 & 195 & 23.9 & 201.7 & & \\
\hline \multirow{8}{*}{$\begin{array}{l}\frac{1}{0} \\
\frac{\pi}{\pi} \\
3 \\
\Xi \\
\Xi\end{array}$} & $\mathrm{W}-1$ & 1.0 & Steel & 48 & 393 & 47.2 & 415.2 & \multirow{8}{*}{$\begin{array}{l}\ldots \\
41\end{array}$} & \multirow{8}{*}{$\begin{array}{l}147 \\
147 \\
172\end{array}$} & \multirow{8}{*}{$\begin{array}{l}10.3 \\
36.6\end{array}$} & & \multirow{8}{*}{$\begin{array}{l}11.5 \\
39.1\end{array}$} & \multirow{8}{*}{$\begin{array}{l}128.8 \\
131.6 \\
180.5\end{array}$} \\
\hline & $\mathrm{W}-2$ & 3.0 & Free & & & & & & & & 154.3 & & \\
\hline & $\mathrm{W}-3$ & 3.0 & Acrylite & & & & & & & & 156.9 & & \\
\hline & $\mathrm{W}-4$ & 4.0 & Steel & & & & & & & & 206.5 & & \\
\hline & $\mathrm{W}-5$ & 4.9 & Free & & 390 & & 397.2 & & & & & & \\
\hline & $\mathrm{W}-6$ & 4.9 & Acrylite & $\ldots$ & 390 & 9.7 & 397.9 & & & & & & \\
\hline & $\mathrm{W}-7$ & 4.9 & Steel & 47.5 & 392 & 44.6 & 413.9 & & & & & & \\
\hline & $\mathrm{W}-8$ & 10.0 & Steel & 50 & 370 & 42.9 & 413.6 & & & & & & \\
\hline
\end{tabular}

Note $* y_{1}$ and $y_{2}$ are in phase in 1 st mode and out of phase in 2 nd mode.

** $m_{w 3}$ is neglected in calculation.

*** Spring constant of suspender, evaluated by static deflcttion test, $k_{2}=1900 \mathrm{~kg} / \mathrm{cm}$ for steel stay, $83 \mathrm{~kg} / \mathrm{cm}$ for acrylite stay 
Table 2.3 Ratio of frequency in water to that in air of models

\begin{tabular}{|c|c|c|c|c|c|c|c|c|}
\hline \multirow{2}{*}{ Suspender } & \multirow{2}{*}{ Case } & \multicolumn{3}{|c|}{1 st mode } & \multicolumn{3}{|c|}{2 nd mode } & \multirow{2}{*}{ Model } \\
\hline & & Measured & Culculated & Meas./Cal. & Measured & Calculated & Meas./Cal. & \\
\hline Free & $\frac{W-5}{A-1}$ & & & & 0.813 & 0.827 & 0.983 & \multirow{5}{*}{ Model A } \\
\hline \multirow{3}{*}{ Steel } & $\frac{W-1}{A-2}$ & 0.640 & 0.524 & 1. 221 & 0.864 & 0.844 & 1.022 & \\
\hline & $\frac{W-7}{A-2}$ & 0.633 & 0.496 & 1.276 & 0.862 & 0.841 & 1.024 & \\
\hline & $\frac{W-8}{A-2}$ & 0.666 & 0.477 & 1. 396 & 0.814 & 0.841 & 0.968 & \\
\hline Acrylite & $\frac{W-6}{A-3}$ & $\cdots$ & 0.503 & $\cdots$ & 0.826 & 0.829 & 0.997 & \\
\hline Free & $\frac{W-2}{A-1}$ & & & & 0.735 & $\begin{array}{c}0.772 \\
(0.644)\end{array}$ & $\begin{array}{c}0.952 \\
(1.141)\end{array}$ & \multirow{3}{*}{ Model B } \\
\hline Steel & $\frac{W-4}{A-2}$ & 0.547 & $\begin{array}{c}0.388 \\
(0.414)\end{array}$ & $\begin{array}{c}1.409 \\
(1.320)\end{array}$ & 0.896 & $\begin{array}{c}0.836 \\
(0.739)\end{array}$ & $\begin{array}{c}1.071 \\
(1.212)\end{array}$ & \\
\hline Acrylite & $\frac{W-3}{A-3}$ & $\cdots$ & $\begin{array}{c}0.431 \\
(0.481)\end{array}$ & $\cdots$ & 0.754 & $\begin{array}{c}0.777 \\
(0.652)\end{array}$ & $\begin{array}{c}0.971 \\
(1.157)\end{array}$ & \\
\hline
\end{tabular}

Note Numbers in brackets mean the case neglecting $m_{w 3}$ in calculation.

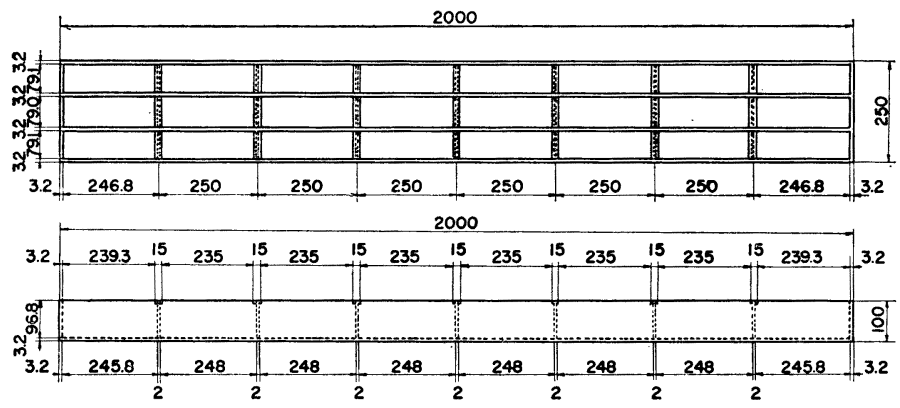

Fig. 2.7 Plan and profile of steel model

tugboat by Kumai11) on the three dimensional correction factor. The correction factor, however, has: not been investigated for the vibration considered in this report. As it is very complicated to study the correction factor theoretically, it is determined in this report by semi-empirical method using the tank part model of a tanker. The model is made of steel and shown in Fig. 2.7. It has the rectangular cross section and no upper deck. The transveres bulkheads except both ends are made of acrylite. Measured results, together with calculated ones, are presented in Tables 2.4 and 2.5 and. Fig. 2.8. The theoretical calculation is made according to the procedure mentioned in the 1 st report. The two-dimensional added mass of water is evaluated as described above.

In the calculation the Townsin's three-dimensional correction factor ${ }^{12}$ ) is used tentatively for the sake of simplicity, although it is not rigorous for the present case*. From the presented results, the followings are concluded.

(a) Calculated results agree with measured ones in general tendency.

* Townsin's reduction factor is proposed for the beam vibration and neglectes the effect of beamdraft ratio for simplification, which is pointed out by Kumai in discussions of reference (12). 
Table 2.4 Comparison between measured and calculated frequency of tank part model

\begin{tabular}{|c|c|c|c|c|c|c|c|}
\hline \multirow{3}{*}{\multicolumn{2}{|c|}{ No. of nodes }} & \multicolumn{3}{|c|}{ In water $(\mathrm{draft}=70 \mathrm{~mm})$} & \multicolumn{2}{|c|}{ In air } & \multirow{3}{*}{ Remarks } \\
\hline & & \multirow{2}{*}{ Measured } & \multicolumn{2}{|c|}{ Calculated } & \multirow{2}{*}{ Measured } & \multirow{2}{*}{$\begin{array}{c}\text { Calculated } \\
N_{a}\end{array}$} & \\
\hline & & & $N_{w 1}$ & $N_{w 2}$ & & & \\
\hline \multirow{7}{*}{$\begin{array}{c}1 \mathrm{st} \\
\text { spectrum }\end{array}$} & 2 & $93 \mathrm{cps}$ & $88.1 \mathrm{cps}$ & $88.1 \mathrm{cps}$ & $138 \mathrm{cps}$ & $136.6 \mathrm{cps}$ & \multirow[b]{7}{*}{$\begin{array}{c}\text { Stern } \\
\text { vibration }\end{array}$} \\
\hline & 3 & 245 & 242.3 & 236.2 & 362 & 373.7 & \\
\hline & 4 & 467 & 453.4 & 435.8 & 685 & 728.2 & \\
\hline & 5 & 694 & 710.1 & 676.9 & 1065 & 1153.3 & \\
\hline & 6 & 928 & 1013.6 & 961.2 & 1658 & 1655.4 & \\
\hline & 7 & 1178 & 1354.3 & 1280.3 & $\cdots$ & $\cdots$ & \\
\hline & 8 & 1323 & $\cdots$ & $\cdots$ & $\cdots$ & $\cdots$ & \\
\hline \multirow{5}{*}{$\begin{array}{c}2 \text { nd } \\
\text { spectrum }\end{array}$} & 2 & 534 & 423.4 & 419.5 & 571 & 471.3 & \\
\hline & 3 & $\ldots$ & 478.6 & 474.7 & 635 & 526.3 & \\
\hline & 4 & 726 & 669.0 & 662.5 & $\ldots$ & 697.8 & \\
\hline & 5 & $\ldots$ & 995.2 & 987.2 & $\ldots$ & 1021.8 & \\
\hline & 6 & & $\cdots$ & 1402.2 & 1472 & 1441.9 & \\
\hline \multicolumn{2}{|c|}{$\begin{array}{l}\text { Reduction } \\
\text { factor }\end{array}$} & & $\begin{array}{c}\text { Townsin's } \\
J_{n}\end{array}$ & $\begin{array}{c}\text { Townsin's } \\
J_{2}\end{array}$ & & & \\
\hline
\end{tabular}

(b) Townsin's reduction factor for 2-noded

Table 2.5 Ratio of frequency in water to that vibration $\left(J_{2}\right)$ may be applicable to the higher mode vibration for the practical use.

(c) Since the effect of the hydrodynamic inertia on the 2 nd spectrum is slight it is im. portant to study the reduction factor for the 1 st spectrum in future works.

\section{Natural frequencies of actual ship}

Using the added virtual mass studied in the preceding section, the calculation of the natura frequency has been carried out again on the ship A, principal particulars of which were presented in the 1 st report. The method is the same that used in the preceding section. The liquid cargo in air of tank part model

\begin{tabular}{|c|c|c|c|c|}
\hline \multirow{2}{*}{\multicolumn{2}{|c|}{$\begin{array}{l}\text { No. of } \\
\text { nodes }\end{array}$}} & \multirow{3}{*}{$\begin{array}{c}\text { Measured } \\
0.674\end{array}$} & \multicolumn{2}{|c|}{ Calculated } \\
\hline & & & \multirow{2}{*}{$\frac{N_{w 1} / N_{a}}{0.645}$} & \multirow{2}{*}{$\frac{N_{w 2} / N_{a}}{0.645}$} \\
\hline$\Xi$ & 2 & & & \\
\hline ב̇ב & 3 & 0.677 & 0.648 & 0.632 \\
\hline 迨 & 4 & 0.682 & 0.623 & 0.598 \\
\hline+ & 5 & 0.652 & 0.616 & 0.587 \\
\hline- & 6 & 0.560 & 0.612 & 0.581 \\
\hline घ & 2 & 0.935 & 0.898 & 0.890 \\
\hline 2 & 3 & $\cdots$ & 0.909 & 0.902 \\
\hline 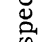 & 4 & $\cdots$ & 0.959 & 0.950 \\
\hline 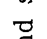 & 5 & $\cdots$ & 0.974 & 0.966 \\
\hline$N$ & 6 & $\cdots$ & $\cdots$ & 0.972 \\
\hline \multicolumn{2}{|c|}{$\begin{array}{l}\text { Reduction } \\
\text { factor }\end{array}$} & & $\begin{array}{c}\text { Townsin's } \\
J_{n}\end{array}$ & $\begin{array}{c}\text { Townsin's } \\
J_{2}\end{array}$ \\
\hline
\end{tabular}
weight is assumed to be perfectly effective for simplification*. Calculated results are presented in Table 3.1 and Figs. 3.1, 3.2 and 3.3 for comparison with measured ones. From these results, the followings are concluded.

(a) The present method shows good agreement of calculated and measured frequencies in the higher mode vibration of ship $A$.

(b) It might be considered that the calculated frequencies in the 1 st report became lower because under-estimation of the shear rigidity and over-esitimation of the added virtual mass of water.

* The effectiveness of the liquid cargo was investigated by Kumai9). 


\begin{tabular}{|c|c|c|}
\hline & measured & calculated \\
\hline S. Shell & $\bullet$ & - \\
\hline L. B hd & 0 & $\cdots$ \\
\hline
\end{tabular}

Table 3.1 Comparison between measured and
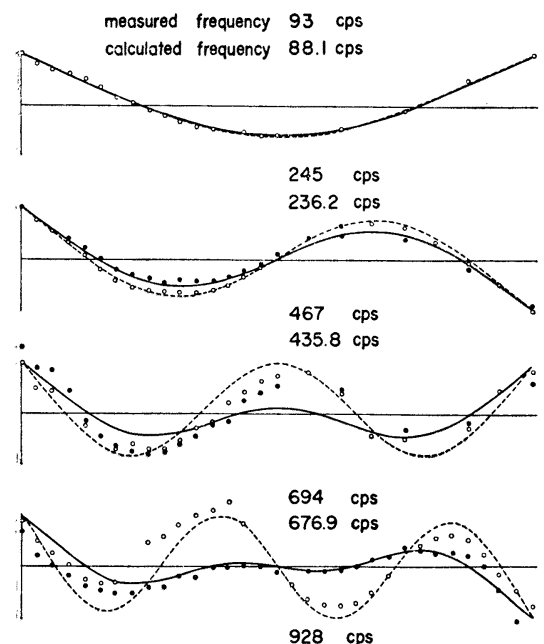

$928 \mathrm{cps}$
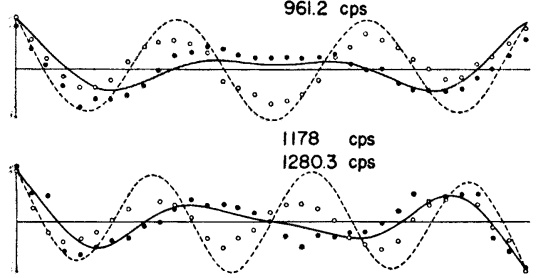

(a) Ist spectrum
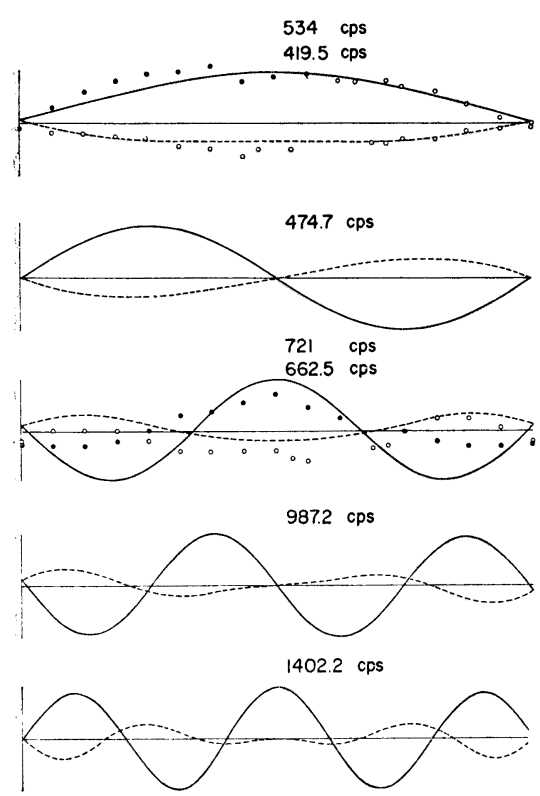

(b) 2nd spectrum

Fig. 2.8 Comparison between measured and calculated mode curves of tank part model in water

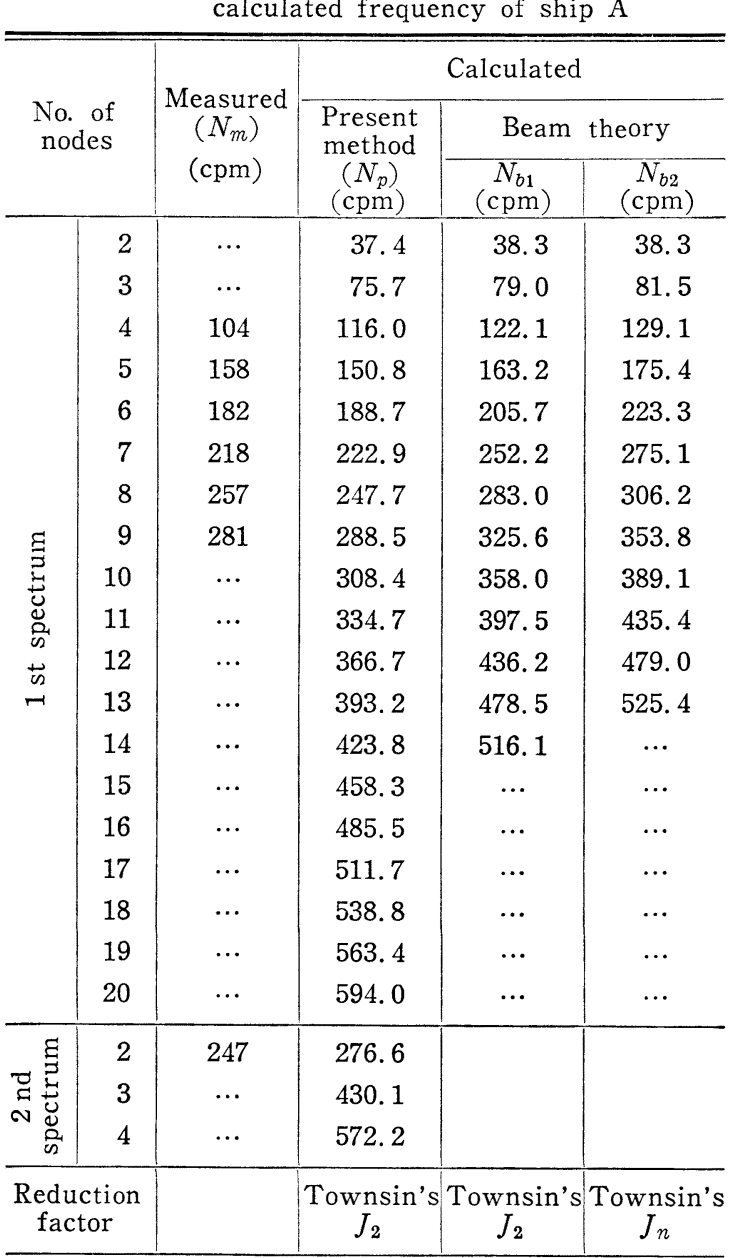

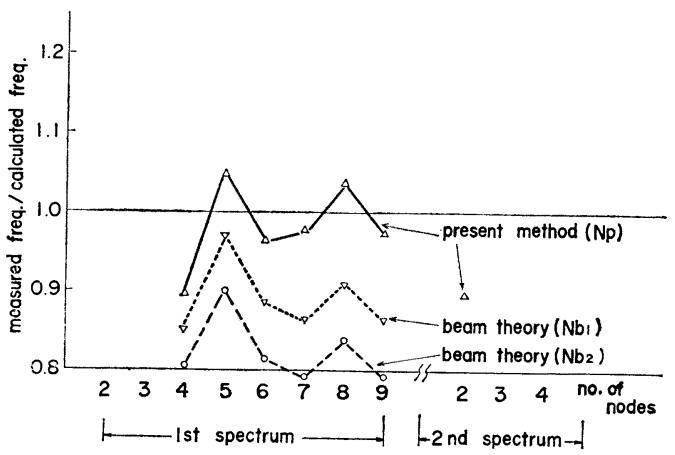

Fig. 3.1 Ratio of measured and calculated frequency of ship A

$\left(N_{p}, N_{b 1}, N_{b 2} ;\right.$ see Table 3.1$)$ 
(c) The unsatisfactory discrepancy of calculated and measured mode curves at after ship, where the extreme stern vibaration is observed, suggests the necessity of future works.

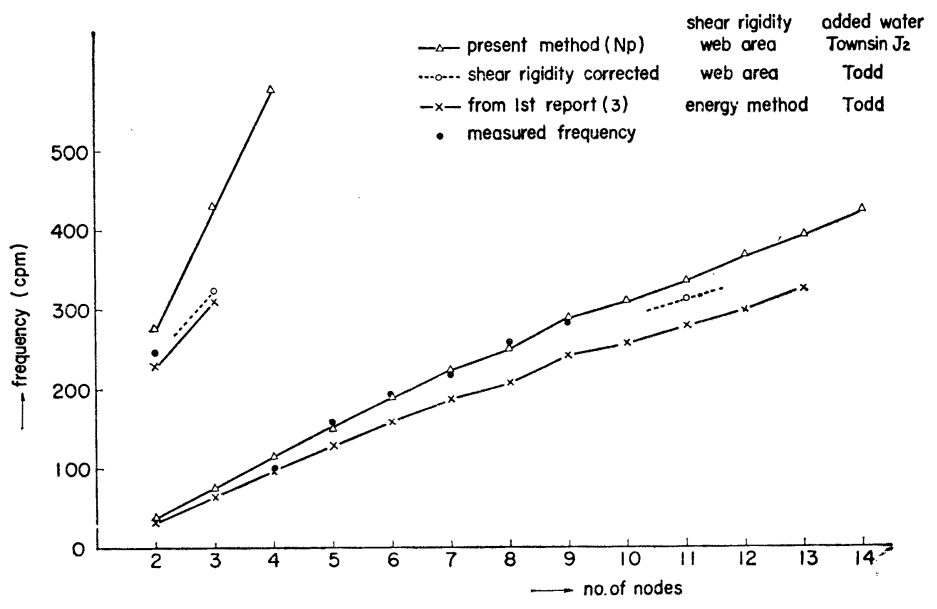

Fig. 3.2 Higher mode vibration of ship A

\section{Response of actual ship}

The transfer matrix method to calculate the response of the higher mode vibration of a giant tanker was developed in the 1 st report where the bending deflection was neglected. The calculated response is shown in Fig. 4.1 where the shear damping only is taken into account for simplification. In the figure the so-called stern vibration is seen in the higher frequency range.

On the other hand, the forced amplitude of the aft end of the ship subjected to a sinusoidal force acting on the end can be expressed by the following analytical equation, provided that the vibratory response is assumed to be the sum of normal functions.

$$
y=\sum_{n=2}^{\infty} \frac{F}{\omega_{n}^{2} \sqrt{\left\{1-\left(\frac{\omega}{\omega_{n}}\right)^{2}\right\}^{2}+\left(\frac{\delta_{n}}{\pi} \cdot \frac{\omega}{\omega_{n}}\right)^{2} \cdot \int_{0}^{L} \frac{w}{g} X_{n}^{2} d x}}
$$

where $y$ : amplitude of vibratory response of ship end

$F$ : amplitude of sinusoidal exciting force acting on ship end

$\omega$ : circular frequency of exciting force

$X_{n}: n^{\prime}$ th normal mode

$\omega_{n}$ : circular frequency of $n^{\prime}$ th normal mode

$\delta_{n}$ : logarithmic decrement of $n^{\prime}$ th nomal mode

$w$ : weight per unit length of ship including added water

$L:$ ship length

$x$ : coordinate along ship length

$g:$ acceleration of gravity

The reciprocal of the mode factor may be defined to be an effective mass coefficient as follows : ${ }^{19)}$

$$
C_{e}=\frac{\int_{0}^{L} \frac{w}{g} X_{n}^{2} d x}{\int_{0}^{L} \frac{w}{g} d x}
$$

For the higher mode vibration of a giant tanker, the effective mass and the total mass are expressed by the following equations. 


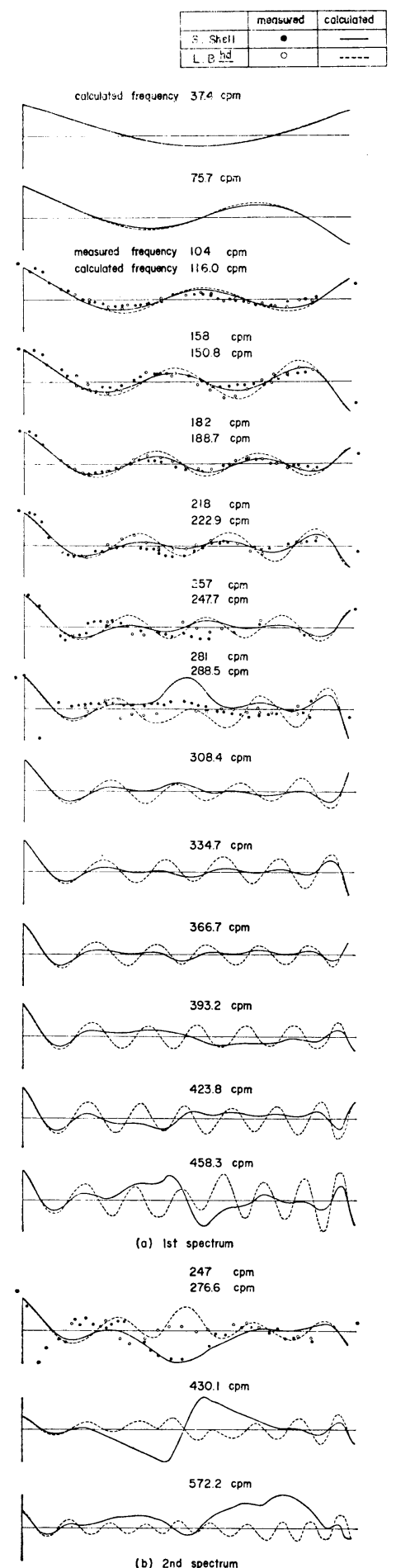

(b) 2nd spectrum

Fig. 3.3 Comparison between measured and calculated mode curves of ship A
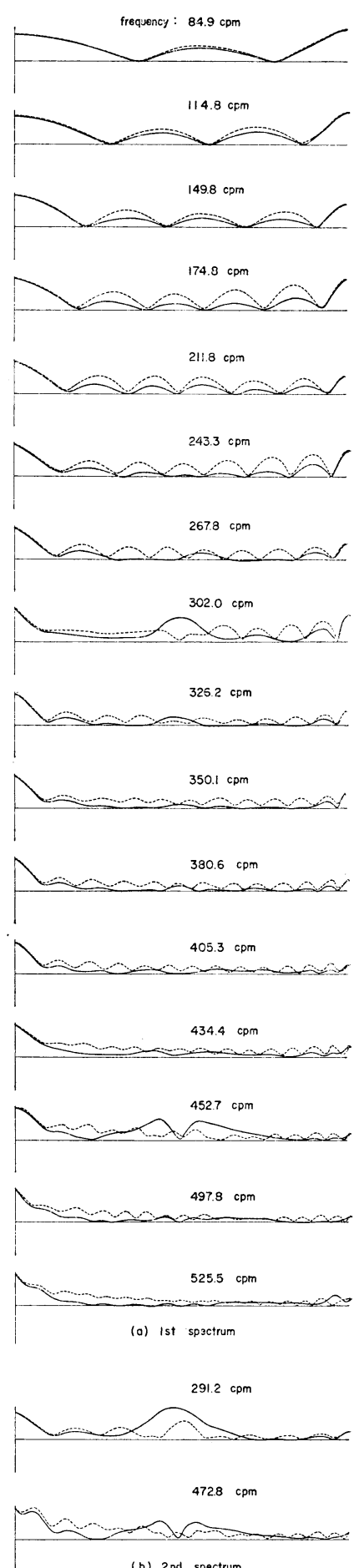

(b) 2nd spectrum

Fig. 4.1 Absolute amplitude and number of nodes of ship $A$ in shear vibration $(\beta=0.001 \mathrm{sec})$ 


$$
\begin{aligned}
& \int_{0}^{L} \frac{w}{g} X^{2} d x=\int_{0}^{L}\left\{\left(m_{1}+m_{W 1}\right) y_{1}^{2}+\left(m_{2}+m_{W 2}\right) y_{2}^{2}+2 m_{W 3} y_{1} y_{2}\right\} d x \\
& \int_{0}^{L} \frac{w}{g} d x=\int_{0}^{L}\left\{m_{1}+m_{W 1}+m_{2}+m_{W 2}+2 m_{W 3}\right\} d x
\end{aligned}
$$

The calculated effective mass coefficient of the normal mode of ship A is shown in Fig. 4.2, where "shear mode" means that the bending deflection is neglected. The effective coefficient undergoes irregular fluctuation with the number of nodes. It may be partly caused by the non-uniform distribution of the weight as was pointed out by $\mathrm{Kumai}^{13)}$, and also by the elastic deformation of the section. In the Fig. 4.2

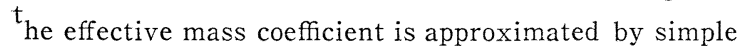
formula shown as "proposed line" which is used later in this report. The total weight of ship $A$ is 256,690 ton including virtual weight of water. For the resonance in the case of small damping, the equation (4.1) can be reduced to the following equation.

$$
\alpha=\frac{\mu}{c_{e} W / g}
$$

where $\alpha$ : acceleration of ship end per unit exciting force acting on ship end

$\mu$ : dynamic magnification factor

$W$ : total weight including added water

In the shear vibration with shear damping, the dynamic magnification factor and the logarithmic decrement are expressed as follows*.

$$
\mu=\frac{1}{\beta \omega}, \quad \delta=\pi \beta \omega
$$

where $\beta$ : shear damping coefficient

For comparison of the response calculated by the transfer matrix method and that calculated by using the equations (4.4) and (4.5), numerical results are presented in Table 4.1. In the table, the effective mass coefficient $\left(c_{e}\right)$ is evaluated by using the absolute amplitude of shear vibration and the equation(4.3). These results show good agreement between the transfer matrix method and analytical method. Decreasing of effective mass coefficient due to the effect of damping is presented in Table 4.2. Thus the following equation is derived.

$$
\alpha=\frac{\mu}{r c_{e} W / g}
$$

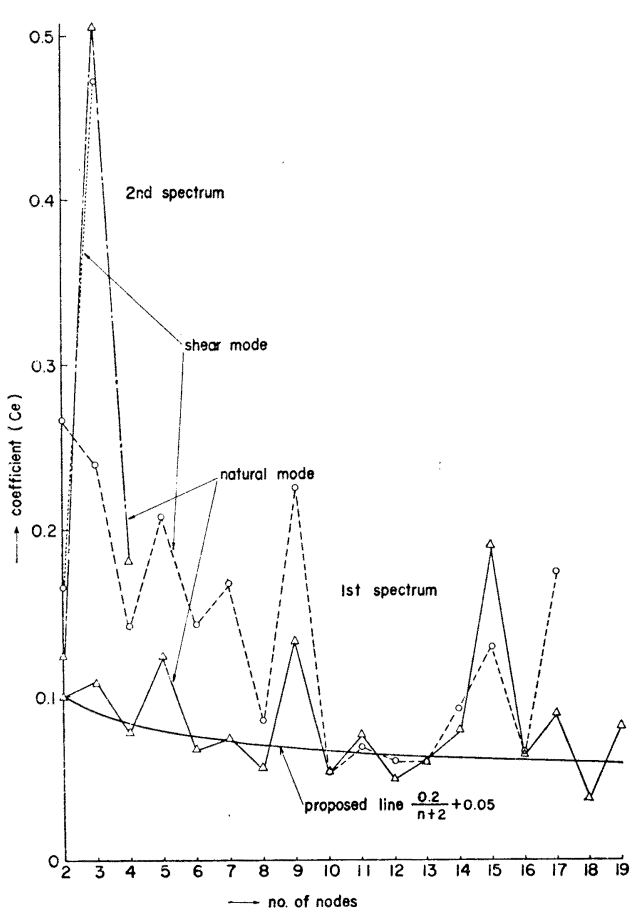

Fig. 4.2 Effective mass coefficient of higher mode vibration of ship $A$

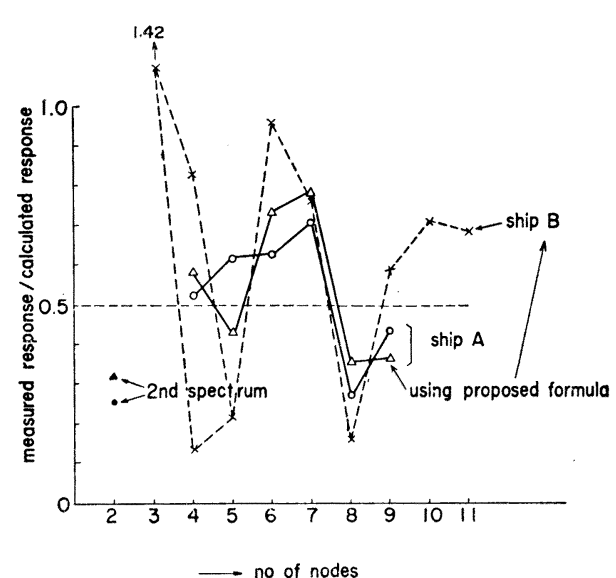

Fig. 4.3 Ratio of measured and calculated response of ship A and ship B

where $r:$ reduction factor of $c_{e}$ due to damping

(ratio of $c_{e}$ in Table 4.2 )

* It is clarified that the effect of non-uniform distribution of damping has little influence on the response of the ship $^{19)}$. 
Table 4.1 Dynamic response of excitation end (aft end) in shear vibration of ship A

\begin{tabular}{|c|c|c|c|c|c|c|c|c|c|c|c|c|}
\hline \multicolumn{3}{|c|}{$\beta$} & \multicolumn{5}{|c|}{$0.001 \mathrm{sec}$} & \multicolumn{5}{|c|}{$0.0005 \mathrm{sec}$} \\
\hline \multicolumn{2}{|c|}{$\begin{array}{l}\text { No. of } \\
\text { nodes }\end{array}$} & $\begin{array}{l}\text { Freq. } \\
(\mathrm{cpm})\end{array}$ & $C_{e}$ & $\mu *)$ & $\begin{array}{c}\left.\alpha_{\mathrm{I}} * *\right) \\
\text { (gal/ton) }\end{array}$ & $\begin{array}{c}\left.\alpha_{\mathrm{II}}{ }^{* * *}\right) \\
(\mathrm{gal} / \text { ton })\end{array}$ & $\alpha_{\mathrm{I}} / \alpha_{\mathrm{II}}$ & $C_{e}$ & $\mu *)$ & $\alpha_{\mathrm{I}}^{* *)}$ & $\left.\alpha_{\mathrm{II}} * * *\right)$ & $\alpha_{\mathrm{I}} / \alpha_{\mathrm{II}}$ \\
\hline \multirow{3}{*}{ 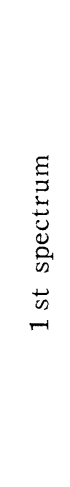 } & $\begin{array}{l}2 \\
3 \\
4 \\
5 \\
6\end{array}$ & $\begin{array}{c}84.883 \\
114.80 \\
149.80 \\
174.80 \\
211.82\end{array}$ & $\begin{array}{l}0.2660 \\
0.2384 \\
0.1405 \\
0.2018 \\
0.1315\end{array}$ & $\begin{array}{r}112.5 \\
83.2 \\
63.8 \\
54.6 \\
45.1\end{array}$ & $\begin{array}{l}1.615 \\
1.332 \\
1.732 \\
1.034 \\
1.309\end{array}$ & $\begin{array}{l}1.653 \\
1.410 \\
1.885 \\
1.142 \\
1.417\end{array}$ & $\begin{array}{l}0.977 \\
0.945 \\
0.919 \\
0.905 \\
0.923\end{array}$ & 0.2403 & $\begin{array}{r}225.0 \\
166.4 \\
127.5 \\
109.3 \\
90.2\end{array}$ & 2.643 & 2.768 & 0.955 \\
\hline & $\begin{array}{r}7 \\
8 \\
9 \\
10 \\
11\end{array}$ & $\begin{array}{l}243.32 \\
267.84 \\
301.99 \\
326.19 \\
350.09\end{array}$ & $\begin{array}{l}0.1251 \\
0.0756 \\
0.1265 \\
0.0473 \\
0.0580\end{array}$ & $\begin{array}{l}39.2 \\
35.7 \\
31.6 \\
29.3 \\
27.3\end{array}$ & $\begin{array}{l}1.198 \\
1.801 \\
0.955 \\
2.364 \\
1.797\end{array}$ & $\begin{array}{l}1.194 \\
1.932 \\
1.083 \\
2.627 \\
1.934\end{array}$ & $\begin{array}{l}1.003 \\
0.932 \\
0.882 \\
0.900 \\
0.929\end{array}$ & $\begin{array}{l}0.1539 \\
0.0825 \\
0.1882 \\
0.0522 \\
0.0654\end{array}$ & $\begin{array}{l}78.5 \\
71.3 \\
63.2 \\
58.6 \\
54.6\end{array}$ & $\begin{array}{l}1.948 \\
3.300 \\
1.283 \\
4.281 \\
3.186\end{array}$ & $\begin{array}{l}2.118 \\
3.650 \\
1.634 \\
4.882 \\
3.450\end{array}$ & $\begin{array}{l}0.920 \\
0.904 \\
0.785 \\
0.877 \\
0.923\end{array}$ \\
\hline & $\begin{array}{l}12 \\
13 \\
14 \\
15 \\
16 \\
17\end{array}$ & $\begin{array}{l}380.62 \\
405.30 \\
434.44 \\
452.71 \\
497.84 \\
525.49\end{array}$ & $\begin{array}{l}0.0492 \\
0.0507 \\
0.0662 \\
0.0809 \\
0.0441 \\
0.0488\end{array}$ & $\begin{array}{l}25.1 \\
23.6 \\
22.0 \\
21.1 \\
19.2 \\
18.2\end{array}$ & $\begin{array}{l}1.946 \\
1.773 \\
1.268 \\
0.996 \\
1.660 \\
1.422\end{array}$ & $\begin{array}{l}2.100 \\
1.981 \\
1.415 \\
1.338 \\
1.774 \\
1.502\end{array}$ & $\begin{array}{l}0.927 \\
0.895 \\
0.897 \\
0.745 \\
0.936 \\
0.947\end{array}$ & $\begin{array}{l}0.0568 \\
0.0585 \\
0.0837 \\
0.1190 \\
0.0582 \\
0.0967\end{array}$ & $\begin{array}{l}50.2 \\
47.1 \\
44.0 \\
42.2 \\
38.4 \\
36.3\end{array}$ & $\begin{array}{l}3.371 \\
3.074 \\
2.005 \\
1.354 \\
2.516 \\
1.435\end{array}$ & $\begin{array}{l}3.697 \\
3.452 \\
2.199 \\
1.985 \\
2.779 \\
1.685\end{array}$ & $\begin{array}{l}0.912 \\
0.891 \\
0.911 \\
0.682 \\
0.906 \\
0.852\end{array}$ \\
\hline 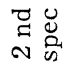 & $\begin{array}{l}2 \\
3\end{array}$ & $\begin{array}{l}291.22 \\
472.77\end{array}$ & $\begin{array}{l}0.1547 \\
0.1040\end{array}$ & $\begin{array}{l}32.8 \\
20.2\end{array}$ & $\begin{array}{l}0.809 \\
0.741\end{array}$ & $\begin{array}{l}1.800 \\
0.864\end{array}$ & $\begin{array}{l}0.450 \\
0.858\end{array}$ & & & & & \\
\hline \multicolumn{2}{|c|}{ Remarks } & \begin{tabular}{|c|} 
Shear \\
Vibration
\end{tabular} & & & & & & & & & & \\
\hline & & & $\mu$ & U & , & $\begin{array}{l}\text { ons } \\
c^{2}\end{array}$ & & $d \mathrm{~b}$ & transt & matrix & method & \\
\hline
\end{tabular}

Table 4.2 Decreasing of effective mass coefficient and dynamic magnification fator in shear vibration of ship A

\begin{tabular}{|c|c|c|c|c|c|c|c|c|c|}
\hline \multicolumn{3}{|c|}{ Case } & \multicolumn{3}{|c|}{ I } & \multicolumn{3}{|c|}{ III } & III \\
\hline \multicolumn{3}{|c|}{$\beta(\sec )$} & \multicolumn{3}{|c|}{0.0005} & \multicolumn{3}{|c|}{0.001} & 0 \\
\hline \multicolumn{3}{|c|}{$\begin{array}{ll} & \text { Item } \\
\begin{array}{l}\text { No. of } \\
\text { nodes }\end{array} & \begin{array}{l}\text { Freq. } \\
(\mathrm{cpm})\end{array}\end{array}$} & $C_{e}$ & $\underset{\text { (I/III) }}{\text { Ratio of }} C_{e}$ & $\mu^{*}$ & $C_{e}$ & $\underset{\text { (II/III) }}{\text { Ratio of }} C_{e}$ & $\mu^{*}$ & $C_{e}$ \\
\hline \multirow{3}{*}{ 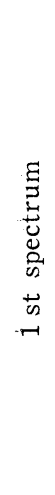 } & $\begin{array}{l}2 \\
3 \\
4 \\
5 \\
6\end{array}$ & \begin{tabular}{|c|}
84.883 \\
114.80 \\
149.80 \\
174.80 \\
211.82
\end{tabular} & 0.2403 & 1.003 & 174.2 & $\begin{array}{l}0.2660 \\
0.2384 \\
0.1405 \\
0.2018 \\
0.1315\end{array}$ & $\begin{array}{l}0.999 \\
0.995 \\
0.994 \\
0.971 \\
0.922\end{array}$ & $\begin{array}{r}115.2 \\
88.1 \\
69.4 \\
60.4 \\
48.8\end{array}$ & $\begin{array}{l}0.2663 \\
0.2396 \\
0.1414 \\
0.2078 \\
0.1426\end{array}$ \\
\hline & $\begin{array}{r}7 \\
8 \\
9 \\
10 \\
11\end{array}$ & $\begin{array}{l}243.32 \\
267.84 \\
301.99 \\
326.19 \\
350.09\end{array}$ & $\begin{array}{l}0.1539 \\
0.0825 \\
0.1882 \\
0.0522 \\
0.0654\end{array}$ & $\begin{array}{l}0.920 \\
0.972 \\
0.836 \\
0.974 \\
0.962\end{array}$ & $\begin{array}{l}85.3 \\
78.9 \\
80.6 \\
66.8 \\
59.1\end{array}$ & $\begin{array}{l}0.1251 \\
0.0756 \\
0.1265 \\
0.0473 \\
0.0580\end{array}$ & $\begin{array}{l}0.748 \\
0.890 \\
0.562 \\
0.882 \\
0.852\end{array}$ & $\begin{array}{l}39.1 \\
38.2 \\
35.9 \\
32.5 \\
29.4\end{array}$ & $\begin{array}{l}0.1672 \\
0.0849 \\
0.2250 \\
0.0536 \\
0.0680\end{array}$ \\
\hline & $\begin{array}{l}12 \\
13 \\
14 \\
15 \\
16 \\
17\end{array}$ & $\begin{array}{l}380.62 \\
405.30 \\
434.44 \\
452.71 \\
497.84 \\
525.49\end{array}$ & $\begin{array}{l}0.0568 \\
0.0585 \\
0.0837 \\
0.1190 \\
0.0582 \\
0.0967\end{array}$ & $\begin{array}{l}0.947 \\
0.974 \\
0.915 \\
0.923 \\
0.891 \\
0.557\end{array}$ & $\begin{array}{l}55.0 \\
52.9 \\
48.2 \\
61.9 \\
42.4 \\
42.7\end{array}$ & $\begin{array}{l}0.0492 \\
0.0507 \\
0.0662 \\
0.0809 \\
0.0441 \\
0.0488\end{array}$ & $\begin{array}{l}0.820 \\
0.844 \\
0.723 \\
0.627 \\
0.676 \\
0.281\end{array}$ & $\begin{array}{l}27.1 \\
26.3 \\
24.5 \\
28.3 \\
20.5 \\
19.2\end{array}$ & $\begin{array}{l}0.0600 \\
0.0601 \\
0.0915 \\
0.1289 \\
0.0653 \\
0.1735\end{array}$ \\
\hline 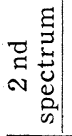 & $\begin{array}{l}2 \\
3\end{array}$ & $\begin{array}{l}291.22 \\
472.77\end{array}$ & & & & $\begin{array}{l}0.1547 \\
0.1040\end{array}$ & $\begin{array}{l}0.936 \\
0.239\end{array}$ & $\begin{array}{l}72.9 \\
77.2\end{array}$ & $\begin{array}{l}0.1653 \\
0.4350\end{array}$ \\
\hline \multicolumn{2}{|c|}{ Remarks } & $\begin{array}{c}\text { Shear } \\
\text { vibration }\end{array}$ & & & & & & & $\begin{array}{c}\text { Normal } \\
\text { mode }\end{array}$ \\
\hline
\end{tabular}

* Deteamined so that $\alpha_{\mathrm{I}}$ coincides with $\alpha_{\mathrm{II}}$ in Table 4.1 
Dynamic response of ship A calculated by the equation (4.6) using values of $c_{e}$ of natural mode in Fig. 4.2 and $\mu$ and $r$ for $\beta=0.001 \mathrm{sec}$ in Table 4.2 is shown in Fig. 4.3. In the figure, there are response of ship B and another result of ship A, which are calculated also by the equation (4.6) but using the following proposed formula derived from $c_{e}$ in Fig. 4.2 and $\mu$ and $r$ for $\beta=0.001$ sec in Table 4.2.

$$
\begin{aligned}
c_{e} & =\frac{0.2}{n+2}+0.05 \\
\mu & =\frac{400}{n+2} \\
r & =\frac{1}{1+0.1\left(\frac{n}{10}\right)^{4}}
\end{aligned}
$$

where $n$ : number of nodes

These proposed formulae are shown in Figs. 4.4, 4.5 and 4.6. From above-mentioned results, follwings are concluded.

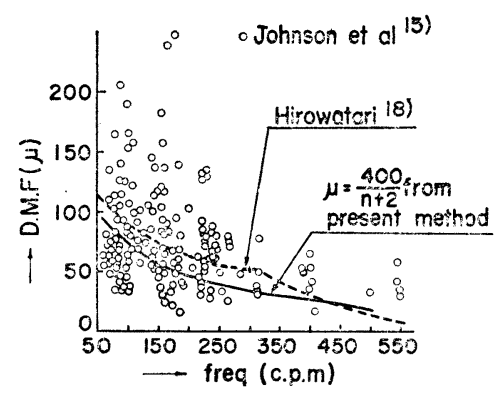

Fig. 4.5 Dynamic magnification factor $(\mu)$

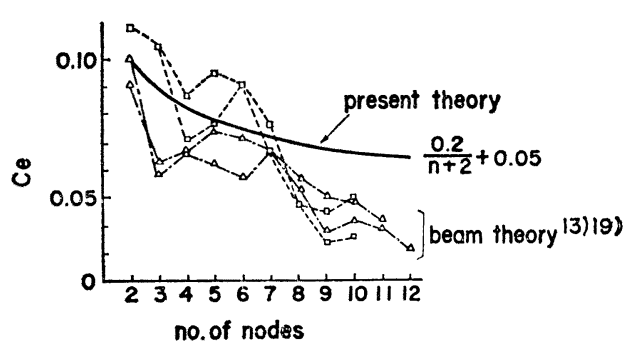

Fig. 4.4 Fffective mass coefficient in higher mode vibration

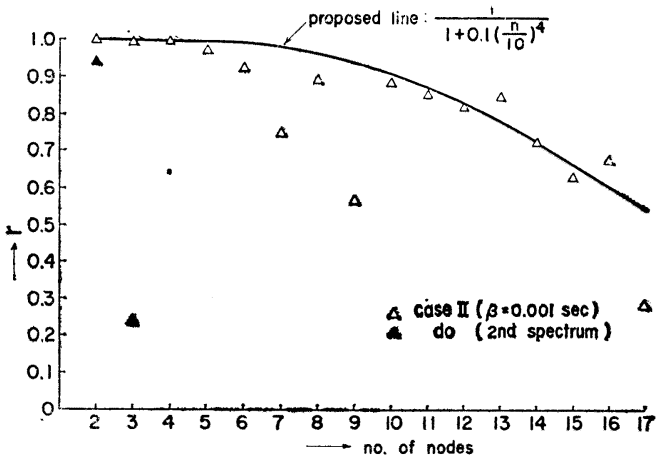

Fig. 4.6 Reduction factor $(r)$ of effective mass coefficient $\left(c_{e}\right)$ of ship A

(a) The rough value of response of the higher mode vibration of a giant tanker may be estimated by the equations (4.6) and (4.7) with empirical factor of 0.5 .

(b) It is necessary to study more precisely the response of a giant tanker in future works.

\section{Conclusive remarks}

A treatment of hydrodynamic inertia for the higher mode vertical vibration of a giant tanker has been studied by theoretical and experimental procedures. The calculation of the frequency and the response of the ship has been made and compared with the measured results. Although the theoretical. results agree with the measured ones in general, the followings need future works.

(a) Three dimensional reduction factor for the effect of hydrodynamic inertia in the higher mode vibration of giant tankers.

(b) Effect of such local structures on the higher mode vibration of giant tankers as double bottom in engine room, propulsion system and superstructure.

(c) Damping mechanism and response in higher mode vibration of giant tankers.

The authors express their hearty gratitude to Professor T. Kumai for his kind advice and to Mr. M. Nakano and Mr. T. Hara for their sincere cooperation in model experiments.

\section{References}

1) Kumai, T. : "Vibration of a Mammoth Tanker with Special Consideration to Athwartship Flexibility”, JSNA West Japan, No. 33 (1967) 
2) Shimizu, S. and Sato, M. : "Shear Vibration of Grillages", JSNA West Japan, No. 37 (1969)

3) Ohtaka, K., Kagawa, K. and Yamamoto, T.: "Higher Mode Vertical Vibration of Giant Tanker (1st report)", JSNA Japan, Vol. 125 (1969)

4) Matsumoto, K. : "On the Non-Beam Vibration of Huge Vessels", JSNA Japan, Vol. 125 (1969)

5) Kumai, T. : "Vibration of a Mammoth Tanker-II (Added Virtual Mass of Water)", Structural Committee Report 61-11-1/2 (1967)

6) Ohtaka, K. and Kagawa, K. : “Added Weight of Water of Giant Tanker", Structuaal Cmmittee Report 73-32-2/2 (1969)

7) Matsumoto, K. : “Added Weight of Water of Non-Beam Vibration”, Vibration Committee Report V 53-7 (1970)

8) Kumai, T. : "Influence of the Virtual Inertia of Vibrating Bottom Panels on the Hull Natural Frequencies”, JSNA West Japan, No. 39 (1970)

9) Kumai, T. : "On the Apparent Mass of Cargo Oil in Ship Vibration”, JSNA Japan, Vol. 117 (1965)

10) Matsuura, Y. : "An Analysis of Vertical Vibration of Cargo Ships", JSNA Japan, Vol. 108 (1960)

11) Kumai, T., Matsumoto, T. and Kaneko, Y.: "Vibration Test in Air on a 200 ton Tugboat and Estimate of Virtual Inertia Coefficient”, JSNA West Japan, No. 25 (1963)

12) Townsin, R. L. : "Virtual Mass Reduction Factors", Quarterly Trans. RINA, Vol. 111, No. 3 (1969)

13) Kumai, T., Tomita, T. and Ochi, Y.: "On the Mode Factor in the Calculation of Response of the Higher Mode of the Vibration of Ships", JSNA West Japan, No. 26 (1963)

14) Kumai, T. : "Damping Factors in the Higher Modes of Ship Vibration", JSNA Japan, Vol. 102 (1957)

15) Johnson, A. J. and Ayling, P. W. : "On the Vibration Amplitudes of Ship's Hulls", Trans. Inst. Engrs. \& Shipbuilders in Scotland (1962)

16) Kumai, T. : "On the Effects of Shear Deflection and Rotatory Inertia Upon the Damping of Ship Vibrations in the Higher Modes", JSNA Japan, Vol. 115 (1964)

17) Yamamoto, Y. and Arita, M. : "Damping Forces in Ship Vibration", JSNA Japan, Vol. 118 (1965)

18) Hirowatari, T. : "Magnification Factors in the Higher Modes of Ship Vibrations", JSNA Japan, Vol. 113 (1963)

19) Ohtaka, K., Nakano, M. and Onoue, M. : "Hull Vibration Caused by Unbalanced Force and Moment of Diesel Engine”, Technical Review of MHI. Ltd., Vol. 5, No. 5 (1968)

20) Matsuura, Y., Kawakami, H. and Onoki, H. : "Study on the Coupled Torsional and Flexural Vibration of Ships with Large Hatch Openings (5th report)-Coupled Torsional and Flexural Vibration of a Bar with Open Cross Section in Water", JSNA Kansai No. 132 (1969) 